\title{
Pulmonary artery banding and subsequent repair in ventricular septal defect
}

\author{
R. G Patel, H. N. C. Ihenacho, L. D. Abrams, R. Astley, C. G. Parsons, \\ K. D. Roberts, and S. P. Singh \\ From The Children's Hospital, Ladywood Middleway, Ladywood, Birmingham
}

Fifty-four patients required pulmonary artery banding in the period Fanuary 1966 to April 1972 for isolated or complicated ventricular septal defects. The main indication for the procedure was intractable congestive cardiac failure not responding to medical therapy. There was a 12 per cent mortality. Complications resulting from the operation are recorded. Twenty of these children have subsequently undergone repair of the ventricular septal defect and reconstruction of the pulmonary artery with a mortality of 30 per cent. To reduce these high risks, the second operation should be performed as early as possible, before secondary changes have resulted from the presence of the band. In the near future the operative mortality should be more acceptable when primary repair is undertaken in infants under the age of 6 months, using profound hypothermia. Primary repair is certainly preferable to banding for patients over 6 months of age.

During infancy, ventricular septal defects with excessive pulmonary blood flow and pulmonary hypertension can posea considerable problem in management. Such cases have a high morbidity and appreciable mortality with medical therapy (Coleman, 1965; Ritter et al., 1965; Nadas, 1967; Hoffman, 1968). However, surgical repair of ventricular septal defects with severe pulmonary hypertension, especially in the first six months, also has a high mortality (Hallman, Cooley, and Bloodwell, I966; Sigmann, Stern, and Sloan, 1967). Hence, pulmonary artery banding may be preferred in these selected cases. It can reduce excessive blood flow and prevent the development of pulmonary vascular disease (Muller and Dammann, 1952; Craig and Sirak, 1963; Goldblatt et al., 1965). Subsequent repair of the ventricular septal defect and reconstruction of the pulmonary artery may then be done after two or three years (Hallman et al., I966; Stark et al., 1970).

\section{First operation: pulmonary artery banding}

Clinical material Fifty-four infants with a ventricular septal defect were treated by pulmonary artery banding between January 1966 and April 1972. All these patients presented with dyspnoea and failure to thrive; they had rib recession in inspiration and many of the babies had to be fed by gastric tube. Operation was undertaken when heart failure would not respond to intensive medical treatment with digoxin, diuretics, and oxygen, and when survival appeared to be unlikely

Received 13 November 1972. without operation. This applied especially to infants under the age of 6 months (43 patients). Two children were over I year old at the time of banding.

Forty of these patients were investigated fully by cardiac catheterization before operation; in II the diagnosis was confirmed by venous angiocardiography alone; and in 3 pulmonary artery banding was carried out as an emergency measure without investigation because the infants' condition was so precarious. Cardiac catheterization was performed under general anaesthesia with the patients breathing 40 per cent oxygen. In all cases pulmonary blood flow was at least twice systemic flow and the systolic peak pressure in the pulmonary artery was more than two-thirds of systemic arterial pressure. The effect of alpha blockade, for example with tolazoline, was not assessed.

Surgical procedure Pulmonary artery banding was carried out through a left lateral thoracotomy and a nylon tape $0.3 \mathrm{~cm}$ wide was used for the ligature. On 3 occasions the band was secured by additional stitches. If a persistent ductus arteriosus and/or coarctation of the aorta were present in addition to the septal defect these were corrected and the pulmonary artery was banded only when this failed to reduce the pulmonary artery pressure sufficiently. The correct tension on the band was judged in most cases by recording the pulmonary artery pressure distal to the constriction. When this could not be done the pulmonary artery was narrowed to between one-third and one-half of the original diameter - just short of causing cardiac arrest.

Postoperative care Intensive treatment was usually needed. Digoxin was continued and antibiotics were 
given for at least a week. Blood $\mathrm{pH}, \mathrm{PCO}_{2}$, and base were measured by the Astrup method using capillary samples unless an indwelling arterial line had been left in position. To aid ventilation after operation an endotracheal tube was left in situ for 24 to 48 hours, but in 12 infants the lungs were so stiff that assisted ventilation had to be continued for a longer period. The endotracheal tube was replaced by a tracheostomy in 4 children who had to be ventilated for more than a week.

Deaths The nature of the cardiovascular lesion is set out in Table I. Seven children died. One death occurred two years after operation when the ligature cut through the pulmonary artery. At necropsy the ventricular septal defect was found to be almost closed and there was an intrapulmonary aneurysm at the site of the band. Six patients died soon after operation and three of these children had complicating cardiovascular anomalies. A baby with coexisting mitral incompetence failed to respond to banding and died after two days. By contrast a baby with complicating aortic coarctation improved after operation but progress was not maintained; pulmonary vascular congestion was again more severe and it was concluded that the band had worked loose. The infant died when the band was replaced. The third baby had a persistent ductus arteriosus in addition to the ventricular septal defect.

Three patients who died had anomalies in other systems - hydrocephalus, cleft palate and hare lip, and phenotype Turner's syndrome with normal chromosomes - but there is no reason to suppose that these were responsible for death.

The mortality rate bore no relation to the age at operation (Fig. I) or to the child's weight at operation (Fig. 2).

Survivors Clinical picture The follow-up period is from 3 months to 6 years. The average weight of patients when dealt with surgically was $4.27 \mathrm{~kg}$. After banding clinical improvement was usually rapid and there was a characteristic growth spurt (Menahem and Venables, 1972).

Haemodynamic findings Before banding most patients had a large left-to-right shunt and pulmonary hyper-

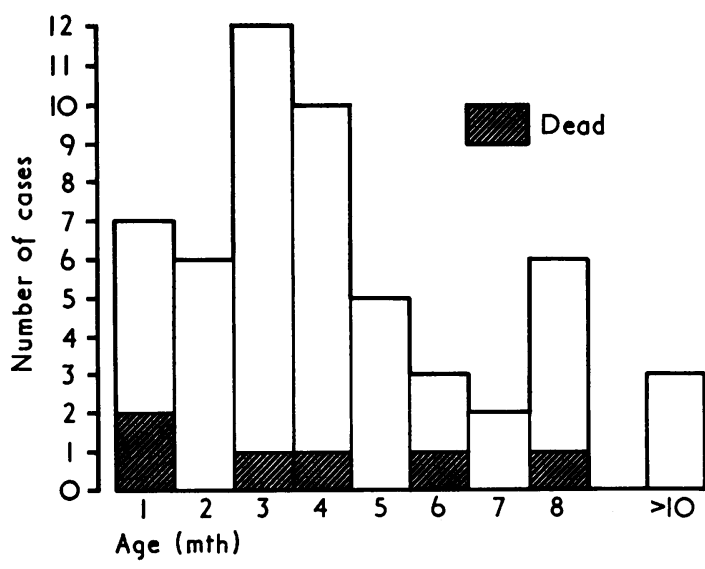

FIG. I Distribution by age at pulmonary artery banding for ventricular septal defect. The hospital mortality is shown.

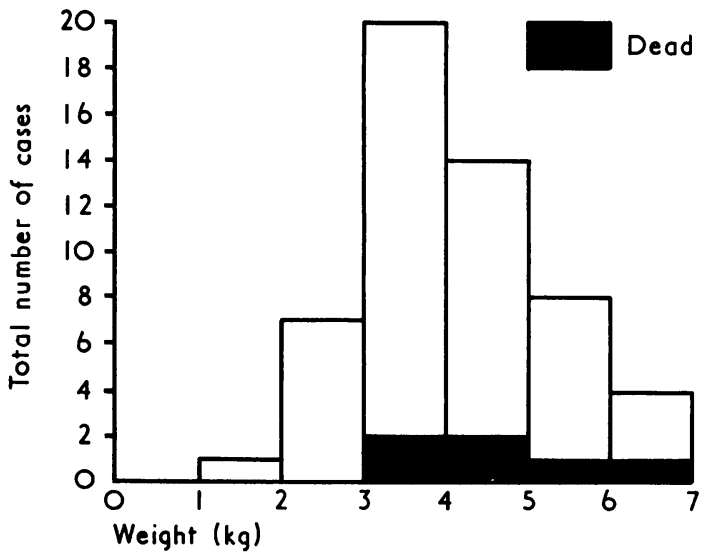

FIG. 2 Distribution by weight at pulmonary artery banding for ventricular septal defect. The hospital mortality is shown.

TABLE I Association between cardiac lesion and mortality from pulmonary artery banding ( 54 cases)

\begin{tabular}{|c|c|c|c|c|c|}
\hline \multirow[t]{2}{*}{ Cardiac lesion } & \multirow{2}{*}{$\begin{array}{l}\text { Total no. } \\
\text { of patients }\end{array}$} & \multirow{2}{*}{$\begin{array}{l}\text { Patients } \\
\text { survived }\end{array}$} & \multicolumn{2}{|l|}{ Deaths } & \multirow{2}{*}{$\begin{array}{l}\text { Mortality } \\
\text { per cent }\end{array}$} \\
\hline & & & Early & Late & \\
\hline $\begin{array}{l}\text { Large VSD } \\
\text { VSD + PDA }\end{array}$ & 32 & 29 & 3 & - & $9 \cdot 4$ \\
\hline VSD + PDA + coarctation of aorta & 3 & $\begin{array}{l}9 \\
1\end{array}$ & I & $\bar{I}$ & $\begin{array}{l}10 \\
66\end{array}$ \\
\hline VSD + coarctation of aorta & $\mathbf{I}$ & $\mathbf{I}$ & - & - & - \\
\hline VSD + ASD & 7 & 7 & - & - & - \\
\hline VSD + mitral incompetence & $\mathbf{I}$ & - & $\mathbf{I}$ & 一 & 100 \\
\hline Total & 54 & 47 & 6 & $\mathbf{I}$ & $12 \cdot 9$ \\
\hline
\end{tabular}


tension. Three patients had multiple ventricular septal defects. Cardiac catheterization has been repeated in $3 \mathbf{I}$ survivors. In 24 of these it was possible to enter the distal pulmonary artery and to assess the degree of constriction by a withdrawal trace. The shunt had decreased in all the 31 patients: in 4 it was from right to left, in 18 it was bidirectional, in 6 it was from left to right, and in 3 no shunt could be demonstrated. Confirmation that the defect had closed spontaneously was obtained when 2 of the patients had their second operation.

The position of the band was demonstrated by biplane cineangiocardiography with contrast medium injected into the right ventricle. The band had slipped up to the bifurcation of the pulmonary artery in 7 patients (Fig. 3 and 4 ) and in 2 others the band had distorted the pulmonary valve, obstructing right ventricular outflow and causing infundibular hypertrophy.

\section{Second operation: removal of band and closure of septal defect}

The mean interval between first and second operations was 3.4 years. In all, 20 patients have undergone the second operation, the approach being through a median sternotomy incision and using a pump oxygenator and moderate hypothermia. The ligature was found at varying positions along the pulmonary artery trunk. It could be removed easily in only 2 cases. Deformity of the artery was such that Io patients required arterioplasty - a longitudinal incision made at the site of constriction being sutured transversely - and in 8 other cases the arterial lumen had to be enlarged with a pericardial patch. An extensive pericardial graft reconstruction was necessary for a child with severe narrowing at the origin of the left pulmonary artery, the result of a band which had slipped. Ventricular septal defects were closed through a right ventriculotomy in all cases except one which was closed through a right atrium. The surgeon felt it desirable to do an infundibulectomy in ro patients to ensure that outflow obstruction was relieved. Two patients had atrial septal defects of the ostium secundum type and these were closed surgically during the course of the operation.

Postoperative care The postoperative course was often stormy, as it was after the first operation. Ventilation was required, usually for 24 to 72 hours, but 8 patients had to be ventilated for a longer period. A 'low cardiac output state' occurred frequently and required the inotropic effects of adrenaline and isoprenaline. One patient developed complete atrioventricular block and has a permanent artificial pacemaker. Nodal rhythm was observed in 6 cases but reverted to sinus rhythm spontaneously within 4 days.

Deaths Six patients died. Dysrhythmia contributed to death in 2,1 of whom developed atrial tachycardia with block on the fifth postoperative day, and the other being readmitted 4 days after discharge from hospital because of atrial tachycardia. Neither patient had received digitalis in the preceding 4 days. Three children died in a 'low cardiac output state' which failed to
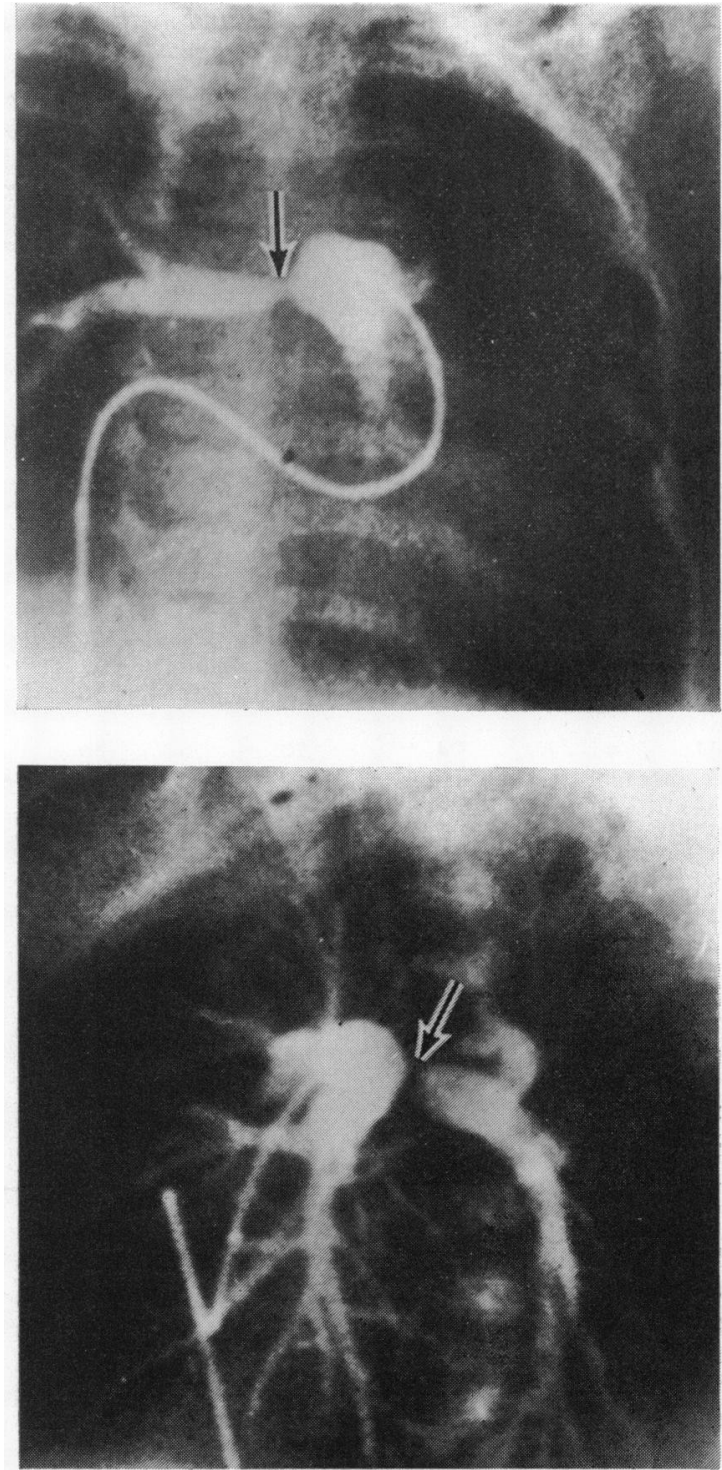

FIG. 3 and 4 Angiocardiogram showing constriction of the main pulmonary artery branches (arrow) due to a slipped ligature.

respond to pressor drugs and fluid replacement. Postoperative bleeding probably contributed to one of these deaths. The sixth child died a few hours after operation and at necropsy was found to have severe pulmonary vascular changes; this patient had failed to maintain the initial improvement which followed banding and corrective surgery was undertaken three months after the first operation. Cardiac catheterization (Case ro, Table 2) had shown a pressure gradient across the band but a raised pressure in the distal pulmonary artery. 
654 Patel, Ihenacho, Abrams, Astley, Parsons, Roberts, and Singh

TABLE 2 Haemodynamic findings and method of reconstruction in 20 patients

\begin{tabular}{|c|c|c|c|c|c|c|c|c|c|}
\hline \multirow[t]{2}{*}{$\begin{array}{l}\text { Case } \\
\text { No. }\end{array}$} & \multirow{2}{*}{$\begin{array}{l}\text { Age when } \\
\text { pulmonary } \\
\text { artery } \\
\text { banded } \\
\text { (mth) }\end{array}$} & \multirow{2}{*}{$\begin{array}{l}\text { Age at } \\
\text { corrective } \\
\text { operation } \\
(y r)\end{array}$} & \multirow{2}{*}{$\begin{array}{l}\text { Main pulm. } \\
\text { artery systolic } \\
\text { pressure before } \\
\text { banding } \\
(\mathrm{mmHg})\end{array}$} & \multicolumn{2}{|c|}{$\begin{array}{l}\text { Systolic pressures after } \\
\text { banding }(\mathrm{mmHg})\end{array}$} & \multicolumn{2}{|c|}{$\begin{array}{l}\text { Systolic pressure after } \\
\text { corrective operation } \\
(\mathrm{mmHg})\end{array}$} & \multirow[t]{2}{*}{ Shunt } & \multirow[t]{2}{*}{$\begin{array}{l}\text { VSD } \\
\text { diameter } \\
(\mathrm{mm})\end{array}$} \\
\hline & & & & $R V$ & $P A$ & $R V$ & $P A$ & & \\
\hline I & 2.5 & 4 & 50 & 74 & 14 & 90 & 40 & Bidirectional & 20 \\
\hline 2 & 15 & 4 & 68 & 85 & 18 & 35 & 25 & Bidirectional & 4 \\
\hline 3 & 2 & 3 & - & 90 & 65 & IIO & - & R-L & Io \\
\hline 4 & 8 & $4 \cdot 5$ & 55 & 82 & 15 & 60 & 50 & L-R & 17 \\
\hline 5 & $2 \cdot 5$ & $1 \cdot 7$ & 50 & 75 & 20 & - & - & - & - \\
\hline 6 & $4 \cdot 5$ & 4 & 65 & 70 & 35 & 40 & 25 & - & 5 \\
\hline 7 & 8 & 3 & 70 & 84 & - & 80 & 25 & Bidirectional & 5 \\
\hline 8 & 2.5 & $4 \cdot 8$ & 40 & 82 & 15 & 60 & 40 & - & - \\
\hline 9 & 10 & 6.8 & 60 & 70 & 35 & 60 & 45 & L-R & 20 \\
\hline ro & 7 & 0.8 & 70 & 80 & 30 & 60 & 20 & Bidirectional & I0 \\
\hline II & 4 & $3 \cdot 4$ & 70 & 80 & 30 & 45 & 35 & $\mathbf{L}-\mathbf{R}$ & 15 \\
\hline 12 & 3 & 5.6 & 75 & 90 & 28 & - & - & $\mathbf{L}-\mathbf{R}$ & 10 \\
\hline 13 & $2 \cdot 5$ & $2 \cdot 6$ & 50 & 90 & 40 & 60 & 30 & Bidirectional & 15 \\
\hline 14 & 5 & $3 \cdot 8$ & 70 & 94 & 25 & - & - & Bidirectional & 15 \\
\hline I5 & 6 & $2 \cdot 8$ & 55 & 98 & 24 & 40 & 40 & Bidirectional & 25 \\
\hline I6 & 2 & $I \cdot 4$ & 58 & 95 & 30 & 60 & 30 & R-L & 13 \\
\hline I7 & 7 & $4 \cdot 8$ & 60 & 115 & 35 & 50 & 30 & Bidirectional & 15 \\
\hline I8 & 8 & $4 \cdot 8$ & 75 & 78 & 20 & 40 & 20 & Bidirectional & 15 \\
\hline 19 & 18 & $4 \cdot 6$ & 65 & 85 & 40 & 30 & - & Bidirectional & 25 \\
\hline 20 & 4 & 6 & 55 & 80 & 30 & 60 & 40 & L-R & 20 \\
\hline
\end{tabular}

Survivors Clinical features Fourteen patients who survived the second operation have remained well over a period ranging from 2 months to 2 years. This includes the child who has complete atrioventricular block which has needed a permanent artificial pacemaker. Three patients have murmurs suggesting that there is a small residual septal defect, but no other disability.

Haemodynamic findings Table 2 gives the data obtained from cardiac catheterization before operation and from direct measurements taken in the theatre after completion of the operation. As might be expected, right ventricular pressure tended to fall and pulmonary artery pressure tended to rise as a result of correction. However, in 2 cases (Cases 4 and 8) pulmonary artery pressure, which had been controlled while the band was in position, rose to prebanding levels after operation and in 4 others (Cases 1, 9, 15, 20) it rose to levels which were above the normal. This appeared to bear no relation to the age at banding or to the initial pulmonary artery pressure, but all these patients had large ventricular septal defects. It can also be seen from Table 2 that
4 patients (Cases I, 7, I3, I6) were left with a pressure gradient of more than $30 \mathrm{mmHg}$ across the right ventricular outflow tract, and 2 of these died.

\section{Discussion}

If an infant with a large left-to-right shunt through a ventricular septal defect, a high pulmonary artery pressure, and heart failure, fails to respond to intensive medical therapy, the chance of survival is remote without surgical treatment (Coleman, I965; Nadas, 1967). The risks of primary repair of the septal defect have been reduced by using profound hypothermia (Kyoto technique, Hikasa et al., r967) and Barratt Boyes has exploited this method with excellent results (Barratt Boyes et al., I97I). However, the operative risks in infants under the age of 6 months are high: DuShane, Weidman, and Ritter (I972) quote a mortality of 22 per cent for severe cases in this age group compared with 4 to 5 per cent in older infants. Though we have included in 


\begin{tabular}{lll}
\hline $\begin{array}{l}\text { Method of closure } \\
\text { of VSD }\end{array}$ & $\begin{array}{l}\text { Reconstruction of } \\
\text { PA and outflow } \\
\text { tract }\end{array}$ & Result \\
& & \\
& & \\
Teflon patch & $\begin{array}{l}\text { Pericardial patch } \\
\text { Arterioplasty, } \\
\text { infundibulectomy }\end{array}$ & $\begin{array}{l}\text { Alive and well } \\
\text { Alive and well }\end{array}$ \\
Teflon patch & $\begin{array}{l}\text { Pericardial patch, } \\
\text { infundibulectomy }\end{array}$ & Alive and well \\
Pericardial patch & $\begin{array}{l}\text { Pericardial patch } \\
\text { Band removed }\end{array}$ & Alive and well \\
(heart block)
\end{tabular}

this series of cases some children whose pulmonary artery was banded after the age of 6 months it is now our practice to advise primary repair for such patients.

Pulmonary artery banding has been shown to reduce pulmonary blood flow and to prevent or cause regression of pulmonary vascular changes (Dammann et al., I96I) but this review of our experience indicates that results are often by no means satisfactory. Seven children out of 54 died after the first operation and the risk did not appear to be linked with the child's age or weight at the time of operation, though the presence of cardiac lesions in addition to the ventricular septal defect probably increased the risk. Only 20 children have yet had the second operation and 6 of these have died. Table 3 summarizes the experience from a number of centres and leads to the conclusion that our present overall mortality of 24 per cent (for both operations) will increase to 30 per cent or more by the time that all patients have had their second operation. Removal of the band, repair of the septal defect, and reconstruction of the pulmonary artery and the right ventricular outflow tract may present serious technical problems

Most of the complications of pulmonary artery banding described in this paper have been reported by other workers. The band may cut through the wall of the pulmonary artery irrespective of the

TABLE 3 Comparison of mortality in published series of repair of ventricular septal defects and pulmonary artery reconstruction after pulmonary artery banding

\begin{tabular}{|c|c|c|c|}
\hline $\begin{array}{l}\text { Author's name and } \\
\text { year }\end{array}$ & $\begin{array}{l}\text { No. of } \\
\text { patients }\end{array}$ & $\begin{array}{l}\text { No. of } \\
\text { deaths }\end{array}$ & $\begin{array}{l}\text { Per cent } \\
\text { mortality }\end{array}$ \\
\hline Dammann et al. (I96I) & II & 4 & $36 \cdot 3$ \\
\hline Hallman et al. (1966) & 14 & $\mathbf{I}$ & $7 \cdot 1$ \\
\hline Stark et al. (1969) & 21 & 6 & $28 \cdot 5$ \\
\hline Hunt et al. (I97I) & 24 & 3 & 12.5 \\
\hline Coleman et al. (1972) & 15 & 4 & $28 \cdot 2$ \\
\hline Present series (1972) & 20 & 6 & 30 \\
\hline
\end{tabular}

material used for the ligature (Rohmer, Brom, and Nauta, 1967; Stark et al., 1970). Migration of the band may constrict the lumen of the main pulmonary artery branches or may lead to deformity and thickening of the pulmonary valve cusps. There may be infundibular muscle hypertrophy (Hunt et al., 1971), and the obstruction may be sufficient to reverse the shunt. Infundibulectomy may be necessary as part of the final surgical repair, but, even so, it may prove impossible to eliminate the gradient between the right ventricle and pulmonary artery. We hope that a pressure gradient of $30 \mathrm{mmHg}$ will not affect the ultimate prognosis and that, since the cause of the infundibular hypertrophy has been removed, the gradient will diminish gradually over the years.

We believe that three quite large ventricular septal defects have closed spontaneously after banding. This has been reported by Hunt et al. (I97I) and by Verel, Chandrasekhar, and Taylor (I97I). The reduction in left-to-right shunt noted after banding may be due in part to a closing septal defect (Coleman et al., 1972) but it can be seen from Table 2 that banding will diminish or reverse a shunt even when a large septal defect is present.

Postoperative dysrhythmias were usually of short duration. Complete atrioventricular block requiring permanent artificial pacing is an unfortunate complication which might have occurred after primary repair; banding cannot be blamed. Two patients had atrial tachycardia shortly after the first operation: both died; neither was taking digitalis at the time. 
Banding certainly lowered pulmonary artery pressure (Table 2) but it did not necessarily control pulmonary hypertension in the long term. We thought that the band might have loosened in two cases, an experience recorded by Stark and his colleagues in 1969 and by Menahem and Venables in 1972 . Both these children died, one after a second banding operation and one after corrective surgery. In the second of these the band was tight enough to produce a pressure gradient, but at necropsy severe pulmonary vascular changes were demonstrable. Two children in whom pulmonary artery pressure was well controlled by the band had undoubted pulmonary hypertension when the band was removed and the ventricular septal defect closed, and four other patients had similar but less obvious changes. Admittedly postoperative pressures were recorded directly before the child left the operating theatre but the findings are disturbing especially in view of reports from the Mayo Clinic that pulmonary vascular changes may be progressive despite satisfactory closure of the ventricular septal defect (DuShane et al., 1972). If in fact these are examples of infants whose pulmonary vascular bed failed to respond to a reduction of pressure and flow after effective pulmonary artery banding, it cannot be assumed that the response would have been any more favourable if the initial operation had been a primary repair of the septal defect.

It is uncertain what the eventual outcome will be in these cases. Though pressure may fall as time passes it is also possible that the condition will deteriorate. The one child whose cardiac catheterization has been repeated some months after the second operation had normal pressures and no shunt, but further long-term follow-up studies will be undertaken. We have found it impossible to predict which cases will do well after banding. Neither age, nor weight, nor the degree of pulmonary hypertension at the time of the first operation appears to affect the outcome.

\section{References}

Barratt-Boyes, B. G., Simpson, M., Seelye, E., and Neutz, J. (197I). Intracardiac surgery in neonates and infants using profound hypothermia (Kyoto technique). In VI World Congress of Cardiology, 1970. Cardiovascular Research, p. $7 \mathrm{I}$.

Coleman, E. N. (1965). Serious congenital heart disease in infancy. British Heart fournal, 27, 42.

Coleman, E. N., Reid, J. M., Barclay, R. S., and Stevenson, J. G. (1972). Ventricular septal defect repair after pulmonary artery banding. British Heart fournal, 34, 134.

Craig, T. V., and Sirak, H. D. (1963). Pulmonary artery banding; an analysis of 38 cases. Fournal of Thoracic and Cardiovascular Surgery, 45, 599.
Dammann, J. F., McEachen, J. A., Thompson, W. M., Smith, R., and Muller, W. H., Jr. (I96I). The regression of pulmonary vascular disease after the creation of pulmonary stenosis. Fournal of Thoracic and Cardiovascular Surgery, 42, 722.

DuShane, J. W., Weidman, W. H., and Ritter, D. G. (1972). Influence of the natural history of large ventricular septal defects on management of patients. Birth Defects: Original Article Series, Vol. 8, pp. 63-68. Published for the National Foundation - March of Dimes, New York, by Williams and Wilkins, Baltimore.

Goldblatt, A., Bernhard, W. F., Nadas, A. S., and Gross, R. E. (1965). Pulmonary artery banding. Indications and results in infants and children. Circulation, 32, 172.

Hallman, G. L., Cooley, D. A., and Bloodwell, R. D. (1966). Two-stage surgical treatment of ventricular septal defect; results of pulmonary artery banding in infants and subsequent open-heart repair. Fournal of Thoracic and Cardiovascular Surgery, 52, 476.

Hikasa, Y., Shirotani, H., Satornura, K., Muraoka, R., Abe, K., Tsushimi, K., Yokota, Y., Mibi, S., Kawai, J., Mori, A., Okamoto, Y., Koie, H., Ban, T., Kanzaki, Y., Yokota, M., Mori, C., Kamiya, T., Tamura, T., Nishii, A., and Asawa, Y. (1967). Open heart surgery in infants with an aid of hypothermic anesthesia. Archiv für japanische Chirurgie, 36, 495.

Hoffman, J. I. E. (I968). Natural history of congenital heart disease; problems in its assessment with special reference to ventricular septal defects. Circulation, 37, 97.

Hunt, C. E., Formanek, G., Levine, M. A., Castaneda, A., and Moller, J. H. (197I). Banding of the pulmonary artery. Results in I I children. Circulation, 43, 395.

Menahem, S., and Venables, A. W. (1972). Pulmonary artery banding in isolated or complicated ventricular septal defects. Results and effects on growth. British Heart fournal, 34, 87.

Muller, W. H., Jr., and Dammann, J. F., Jr. (I952). The treatment of certain congenital malformations of the heart by the creation of pulmonary stenosis to reduce pulmonary hypertension and excessive pulmonary blood flow. Surgery, Gynecology and Obstetrics, 95, 213.

Nadas, A. S. (1967). Management of infants with ventricular septal defect. A controversy. Pediatrics, 39, I.

Ritter, D. G., Feldt, R. H., Weidman, W. H., and DuShane, J. W. (1965). Ventricular septal defect. Circulation, 32, Suppl. 3, p. 42.

Rohmer, J., Brom, A. G., and Nauta, J. (1967). Bands inside the pulmonary artery. A complication of the DammannMuller procedure. Annals of Thoracic Surgery, 3, 449.

Sigmann, J. M., Stern, A. M., and Sloan, H. E. (1967). Early surgical correction of large ventricular septal defects. Pediatrics, 39, 4.

Stark, J., Aberdeen, E., Waterston, D. J., Bonham-Carter, R. E., and Tynan, M. (1969). Pulmonary artery constriction (banding): a report of 146 cases. Surgery, 65, 808 .

Stark, J., Tynan, M., Aberdeen, E., Waterston, D. J., Bonham-Carter, R. E., Graham, G. R., and Somerville, J. (1970). Repair of intracardiac defects after previous constriction (banding) of the pulmonary artery. Surgery, 67, 536.

Verel, D., Chandrasekhar, K. P., and Taylor, D. G. (1971). Spontaneous closure of ventricular septal defect after banding of pulmonary artery. British Heart fournal, 33, 854 .

Requests for reprints to Dr. R. G. Patel, The Children's Hospital, Ladywood Middleway, Birmingham Br6 8ET. 